\title{
Response of Two Libyan Soft Date Cultivars to Induced Ripening Under Controlled Atmosphere Conditions
}

\author{
Mohamed Abusaa Fennir ${ }^{*}$ and Mohamed Taher Morghem ${ }^{2}$ \\ ${ }^{1}$ Associate Professor, ${ }^{2}$ Research Assistant. \\ Department of Agricultural Engineering, Faculty of Agriculture, Tripoli University, Libya \\ *corresponding author: e-mail: m.fennir@uot.edu.ly
}

Received on: 10/11/2019

Accepted on:4/12/2019

\begin{abstract}
Induced ripening under controlled atmosphere (CA) conditions was investigated using two Libyan soft date cultivars, "Bronsi" and "Taboni". An experimental setup consisted of an airtight $15 \mathrm{~L}$ plastic bottle was used, fruits were filled in the setup at $0.6 \mathrm{~kg} . \mathrm{L}-1$ bulk density. The setup was also equipped with valves; facilitating real time monitoring and measurement of oxygen $\left(\mathrm{O}_{2}\right)$, carbon dioxide $\left(\mathrm{CO}_{2}\right)$ and ethylene $\left(\mathrm{C}_{2} \mathrm{H}_{4}\right)$, in addition to temperature and relative humidity inside the enclosure and throughout the treatments. The ripening process was carried out in two stages; an airtight $\mathrm{CA}$ and regular air (RA). In the first stage, fruit ripening was initiated while in the second stage full conversion to Rutab stage and coloring took place. Accumulated $\mathrm{CO}_{2}$ produced was fairly linear for both cultivars, whereas accumulated $\mathrm{C}_{2} \mathrm{H}_{4}$ was linear for "Bronsi" and exhibited polynomial trend for "Taboni" cultivar. However, respiration and $\mathrm{C} 2 \mathrm{H} 4$ production rates did not follow specific trends, instead; they exhibited peaks that were very much related to fruit ripening. Time-wise, the first ripening stage lasted 22 hours for both cultivars, but the second stage lasted 23 hours for "Bronsi" and 45 hours for "Taboni", while ripening percentages for both cultivars exceeded $90 \%$ (w/w). Quality attributes such as color (L, Hue angle and Chroma) and sensory attributes (sweetness, taste and acceptance) for CA induced ripened dates were compared with naturally ripe ones. Results showed no significant differences in color and sensory attributes at $(\mathrm{p}<0.05)$. The study demonstrated the potential of using the method for date ripening. Further investigation using other cultivars and improving the current methodology are highly recommended.
\end{abstract}

KEYWORDS: Induced ripening, Controlled atmosphere, soft dates, ethylene, $\mathrm{CO}_{2}, \mathrm{O}_{2}$

\section{INTRODUCTION}

Date palm (Phoenix dactyliferaL.) is perhaps the most important tree in countries located in dry and semidry regions, mainly North Africa and Middle East. In 2014, the world date production exceeded 7.6 million metric tons; nearly $89 \%$ was produced in the two regions (Al-Yahyai and Manickavasagan, 2012; FAO,2018). Libya attains the tenth place among the world top date producers (Kader and Awad, 2009); in 2014, its production exceeded 172 thousand metric tons (FAO, 2018). Moreover, it has a unique climate, varying from warm Mediterranean to deep dry Sahara proper, offering suitable conditions for growing the three date variety groups. Soft cultivars are cultivated in the coastal region, semidry are in the middle, while dry dates are grown in Sahara oases far south (Fennir et al., 2014). Nearly 400 cultivars exist, yet around 95 are considered commercially important Racchi et al., 2014)

Date production in Libya is subjected to severe losses due to poor postharvest and handling practices, in addition to virtual absence of appropriate postharvest technologies and infrastructures. In fact, substantial losses occur during harvesting, especially in the coastal region, where harvesting ripe dates is generally made in several pickings. Between pickings, fruits are subjected to falling, rotting, souring, in addition to losses caused by insects, birds and other means. Additionally, substantial losses are linked to diseases and physical damage, due to improper packaging and drudgery handling. In southern regions however, insect infestation and sever dryness are the main cause of losses.

From physiological point of view, dates are climacteric fruits, their respiration and ethylene production rates rapidly increase right before ripening (Marondedze et al., 2014; Abbas and Ibrahim, 1996). Thus, similar to other climacterics, they may have the tendency to ripe after being detached from their mother tree. However, dates have uneven ripening behaviour even within the same bunch, making artificial ripening quite challenging. Nonetheless, ripening is a complex biochemical and genetically programmed process by which major changes in fruit color, texture, flavour and aroma take place (Alexanderand and Grierson, 2002). Ripening itself is a physiological process that makes fruits soft, sweet, attractive and nutritious (Gupta, 2017). Artificial ripening is a treatment of stimulating ripening for most climacteric fruits; it is in fact a common practice in tomatoes and bananas ripening. The process was first discovered by Dmitri Nelyubov in 1901, a Russian botanist who linked ripening to ethylene (Gupta, 2017). The process became widely used; however, health concerns related to artificial ripening have been reported (Siddiqui and Dhua, 2010). 
For dates in particular, artificial ripening (induced ripening) of all means may have advantages of reducing losses, securing clean and healthy dates, particularly fresh consumed, in addition to avoiding losses due to rainfall and weather related effects (Abul-Soad, 2010). In fact, the first use of chemical treatment for date ripening by $\mathrm{CO}_{2}$ was reported in 1913 in Arizona, USA (McCarthy, 2012). Incubation was also tested earlier than that on Deglet Noor dates in the same state (Rygg, 1975). However, quite limited studies have been carried out using $\mathrm{CO}_{2}$, but chemical treatments using other agents are common, yet they are criticised for rendering quality and shortening shelf life, in addition to some health concerns. Nonetheless, sodium chloride $(\mathrm{NaCl})$ and acetic acid $\left(\mathrm{CH}_{3} \mathrm{COOH}\right)$ treatments are commonly used in date ripening (Markhand et al., 2014; Farahnaky et al., 2009; Jahromi, 2015). Moreover, physical treatments such as hot water dipping have been investigated (Shamim et al., 2013). In Libya however, research on date ripening is very scarce, apart from that, using vinegar for ripening is quite common in the coastal region, especially for the purpose of early marketing. However, it is criticized for distressing quality and shelf life.

This study aimed at investigating conditions for inducing ripening of two soft date cultivars by applying controlled atmosphere at high $\mathrm{CO}_{2}$ and selfproduced ethylene $\left(\mathrm{C}_{2} \mathrm{H}_{4}\right)$. Two important soft date cultivars were targeted in the current investigation, "Bronsi" and "Taboni".

\section{MATERIALS AND METHODS}

\subsection{Dates}

Samples of the two studied cultivars, "Taboni" and "Bronsi" were collected from an orchard located in the suburb of Tripoli. Bunches were cut out in the morning and transported to the Postharvest Laboratory at the Department of Agricultural Engineering, Faculty of Agriculture, Tripoli University. Fruits whereupon detached from strands, sorted, ripe and undesirable units were removed. Selected fruits were washed with fresh water, and surface dried. True density was also determined; fruits were weighed and placed in graduates cylinder filled with water up to known level. Displaced water represented fruit volume and density was calculated using three replicates. Bulk density was also determined from fruit weight entirely fill the enclosure divided by its volume. Both densities were used for calculating respiration and ethylene rates.

\subsection{Enclosure setup}

Ripening setup was consisted of a 15 liter plastic bottle equipped with an airtight lid. The bottle is transparent, enabled sample observation throughout the treatment. On the lid, a tire brass valve was installed and used as an airlock whenever pressure buildup was observed. It was connected to a female brass fitting in which a plastic pipe was tightened from one end and from the other submerged in a vessel full of water. The airlock enabled release of extra gases and maintained near atmospheric pressure inside the enclosure, in addition to facilitating air sampling and analysis. On bottle sides, three other brass valves were installed, enabling measuring $\mathrm{C}_{2} \mathrm{H}_{4}$, $\mathrm{O}_{2}$ and $\mathrm{CO}_{2}$ inside the enclosure. The setup is an improved version of the one used in previous study, detailed description of the setup can be found in (Fennir et al., 2014).

\subsection{Monitoring the ripening process}

The enclosure was kept tightly closed until most of $\mathrm{O}_{2}$ was consumed, replaced by $\mathrm{CO}_{2}$ and pressure built up was observed, whenever that happened, the airlock was installed, ensuring pressure release and enabling the use of $\mathrm{CO}_{2}-\mathrm{O}_{2}$ and $\mathrm{C}_{2} \mathrm{H}_{4}$ analyzers. The process was ended when most fruits inside the enclosure changed color from Balah to Rutab. For "Bronsi" cultivar, fruits changed color from red to dark red near black, while for "Taboni" cultivars fruits changed color from yellow to orange near brown. Fruits then were removed from the enclosure and displayed on flat surface in an air conditioned room in which temperature and relative humidity were measured. Time of the airtight aerated treatments was recorded and percentages of the ripe fruits were determined on mass basis.

\subsection{Air composition measurement}

Air constituent of $\mathrm{O}_{2}$ and $\mathrm{CO}_{2}$ were measured using portable gas analyzer (Model CANAL120 $\mathrm{O}_{2} \&$ $\mathrm{CO}_{2}$ Gas Analyzer, EMCO Packaging Systems Ltd, Kent, CT14 0BD UK). The analyzer draws small volume air sample, analyses it, and displays $\mathrm{O}_{2}$ and $\mathrm{CO}_{2}$ percentage on an LCD screen. Sample analysis was periodically carried out throughout the ripening treatment of each cultivar.

\subsection{Ethylene measurement}

$\mathrm{C}_{2} \mathrm{H}_{4}$ content inside enclosures was measured using ethylene analyzer (Model CI 900 Portable Ethylene Analyzer- CID Bio Science, Camas, WA 98607, USA). The instrument draws air at low flow rate, measures its $\mathrm{C}_{2} \mathrm{H}_{4}$ content as part per million (ppm), in addition to measuring relative humidity and temperature, all were displayed on LCD screen and saved as comma separated values (csv) on an SD card at selectable time interval. The instrument detects $\mathrm{C}_{2} \mathrm{H}_{4}$ between 0.04 to $200 \mathrm{ppm}$, measurements were carried out by the connecting inlet port to one of the valves installed on the enclosure, while the outlet port was connect to another valve, avoiding suction effect of the instrument on fruits. 


\section{Mohamed Abusaa Fennir and Mohamed Taher Morghem., 2019}

2.6.Temperature and relative humidity measurements

Temperature and relative humidity were measured inside the enclosures using IButton temperature and relative humidity logger (Model, DS1923, Maxim Integrated, San Jose, CA 95134 USA). The sensor was configured at 30 minute interval; the IButton is equipped with internal memory in which data was saved as comma separated values (cvs). At the end of the ripening treatment, data was downloaded on a computer as used for analyses using Microsoft Excel 10 (Mittra et al., 2013).

\subsection{Color measurement}

Ripe fruit surface color was measured right after the ripening treatment was ended using handheld Tristimulus reflectance colorimeter (Minolta CR 400, Minolta Corp., New Jersey, USA). Color change was recorded using (Lab color spaces), with ( $\left.\mathrm{L}^{*}\right)$ indicates lightness, ( $\left.\mathrm{a}^{*}\right)$ for chromaticity from green (-) to red $(+)$, while $\left(b^{*}\right)$ represents chromaticity from blue $(-)$ to yellow (+) (Fennir et al., 2017). All measurements were made in ten replicates.

\subsection{Sensory evaluation}

Qualitative descriptive sensory analysis (QDSA) was conducted using 10 untrained taste panel randomly selected from employees and stuff of the department of Agricultural Engineering, Faculty of Agriculture, Tripoli University. Samples of the induced ripening together with naturally ripen fruits were coded and introduced to each member of the panel.Panellists were asked to mark their assessment to sweetness, taste, and acceptance on a $100 \mathrm{~mm}$ scale line, similar to procedures reported by (Oliveira et al., 2011). During trials panellists were separated and fresh water was provided for rinsing between samples. Obtained data was analyzed using ANOVA procedure of Microsoft Excel 10.

\subsection{Ethylene production rate and respiration rate calculations}

Ethylene production rate (EPR) expressed as $\left(\mathrm{mg} \cdot \mathrm{kg}^{-1} \cdot \mathrm{h}^{-1}\right)$ and respiration rate $(\mathrm{RR})$ as $\mathrm{CO}_{2}$ produced $\left(\mathrm{RR}_{\mathrm{CO} 2}\right)$ and as $\mathrm{O}_{2}$ consumed $\left(\mathrm{RR}_{\mathrm{O} 2}\right)$ were calculated using the following relations (Fennir et al., 2014).

$$
\begin{gathered}
E P R=\frac{(\Delta E)\left(V_{e}-V_{f r}\right)}{m_{f r} \Delta T} \\
R R_{C O_{2}}=\frac{\left(\Delta C O_{2} \%\right)\left(V_{e}-V_{f r}\right)}{m_{f r} \Delta T} \\
R R_{O_{2}}=\frac{\left(-\Delta O_{2} \%\right)\left(V_{e}-V_{f r}\right)}{m_{f r} \Delta T}
\end{gathered}
$$

Where:$$
\mathrm{EPR}=\text { Ethylene production rate }\left(\mathrm{mg} \cdot \mathrm{kg}^{-1} \cdot \mathrm{h}^{-1}\right)
$$

$\mathrm{RR}_{\mathrm{CO} 2}=$ Respiration rate as $\mathrm{CO}_{2}$ produced $\left(\mathrm{ml} \cdot \mathrm{kg}^{-1} \cdot \mathrm{h}\right.$ 1)

$\mathrm{RR}_{\mathrm{O} 2}=$ Respiration rate as $\mathrm{O}_{2}$ consumed $\left(\mathrm{ml} \cdot \mathrm{kg}^{-1} \cdot \mathrm{h}^{-}\right.$ $\left.{ }^{1}\right)$

$\Delta \mathrm{E}=$ Difference between two consecutive $\mathrm{C}_{2} \mathrm{H}_{4}$ measurements (ppm)

$\Delta \mathrm{CO}_{2}, \Delta \mathrm{O}_{2}=\mathrm{O}_{2}$ and $\mathrm{CO}_{2}$ difference between two consecutive measurements (\%).

$\mathrm{V}_{\mathrm{e}}=$ Enclosure volume $(\mathrm{ml})$

$\mathrm{V}_{\mathrm{fr}}=$ fruit volume $(\mathrm{ml})$

$\mathrm{m}_{\mathrm{fr}}=$ mass of fruits filled inside the enclosure $(\mathrm{kg})$

$\Delta \mathrm{T}=$ time elapsed between two consecutive $\mathrm{C}_{2} \mathrm{H}_{4}$, $\mathrm{CO}_{2}$, and $\mathrm{O}_{2}$ measurements (h)

$\mathrm{RR}_{\mathrm{CO} 2}=$ Respiration rate as $\mathrm{CO}_{2}$ produced $\left(\mathrm{ml} \cdot \mathrm{kg}^{-1} \cdot \mathrm{h}^{-}\right.$ 1)

$\mathrm{RR}_{\mathrm{O} 2}=$ Respiration rate as $\mathrm{O}_{2}$ consumed $\left(\mathrm{ml} \cdot \mathrm{kg}^{-1} \cdot \mathrm{h}^{-1}\right)$

\section{Results and Discussion}

\subsection{Temperature and relative humidity}

The ripening process was carried out in two stages, controlled atmosphere (CA) and at regular air (RA). The first treatment was ended when most the fruits changed color, while the second treatment was extended until partially ripen fruits completed their ripening and ripe fruits attained cultivar Rutab color. Figure 1 shows temperature and relative humidity of the CA and RA treatments for the two cultivars. Temperature means for "Bronsi" were $\left(28.64^{\circ} \mathrm{C} \pm 0.11\right)$ and $\left(24.44^{\circ} \mathrm{C} \pm 0.44\right)$ for $\mathrm{CA}$ and $\mathrm{RA}$, respectively, while relative humidity means were $(90 \% \pm 2.28)$ and $(68.6 \% \pm 1.9)$, respectively. On the other hand, temperature means for "Taboni" were $\left(27.3^{\circ} \mathrm{C} \pm 0.25\right)$ and $\left(24.75^{\circ} \mathrm{C} \pm 0.48\right)$ for $\mathrm{CA}$ and $\mathrm{RA}$ treatments, respectively, whereas relative humidity means were $(89 \% \pm 1.41)$ and $(65 \% \pm 3.48)$, for CA and RA treatments, respectively. Nonetheless, despite carrying out the two treatments at different times, mainly because the two cultivars normally do not ripe at the same time( "Taboni" rips earlier), temperature and relative humidity conditions were quite similar. Practically, data on monitoring temperature and relative humidity during date ripening is rather scarce. However, data reported in this investigation can be considered as fairly representative.

Time-wise, as it can be observed in Figure 1 that the CA treatment for both cultivars extended for nearly 22 hours, afterwards the RA treatment began. However, the RA treatment was rather different, for "Bronsi" it lasted for 23 hours, whereas for "Taboni" it extended for nearly 45 hours, making "Bronsi" ripened 22 hours earlier. 
Scientific Journal of Agricultural Sciences 1 (2): 00-00, 2019

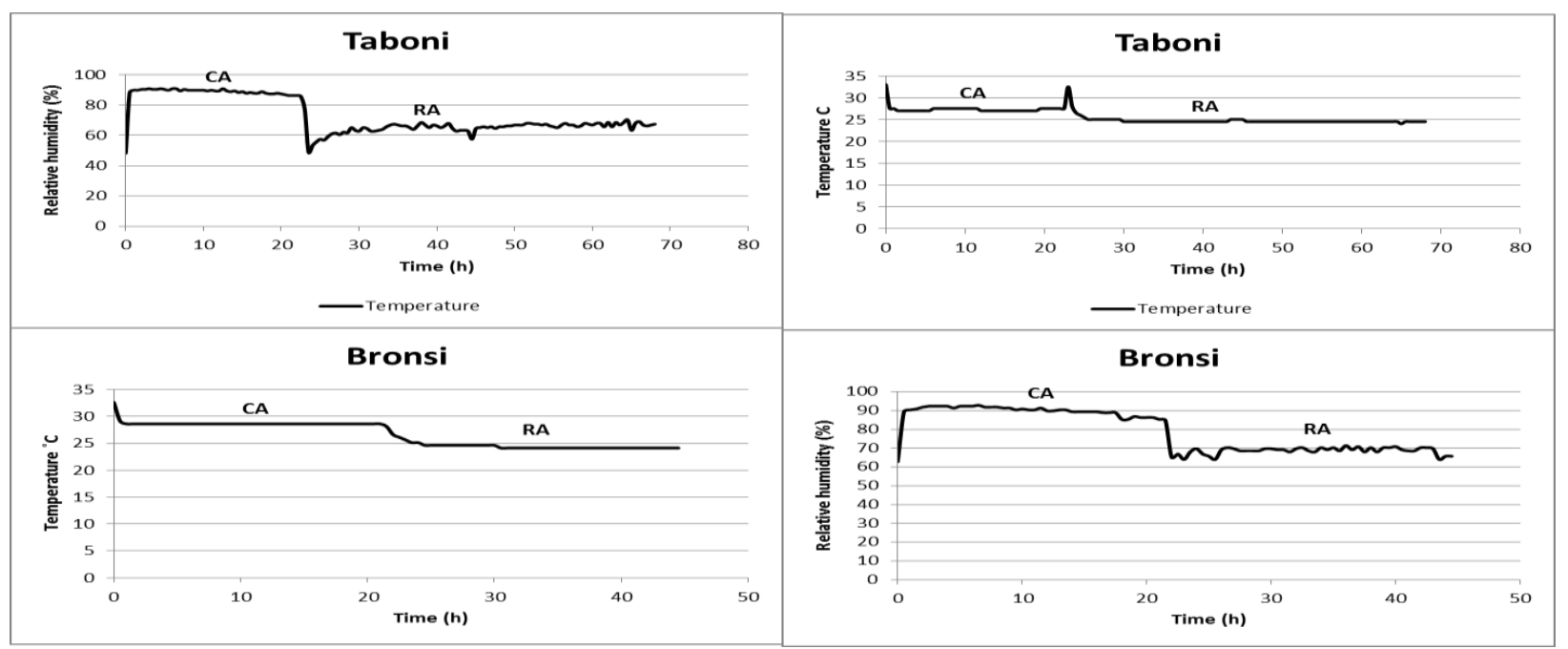

Fig1.Temperature and relative humidity during ripening process

\subsection{Air composition}

During the CA treatment, periodical measurements of $\mathrm{CO}_{2}$ and $\mathrm{O}_{2}$ were made, while $\mathrm{C}_{2} \mathrm{H}_{4}$ was measured by configuring the analyzer on monitoring mode. RR is always considered as the

Fig2. RR and EPR of "Bronsi" under CA

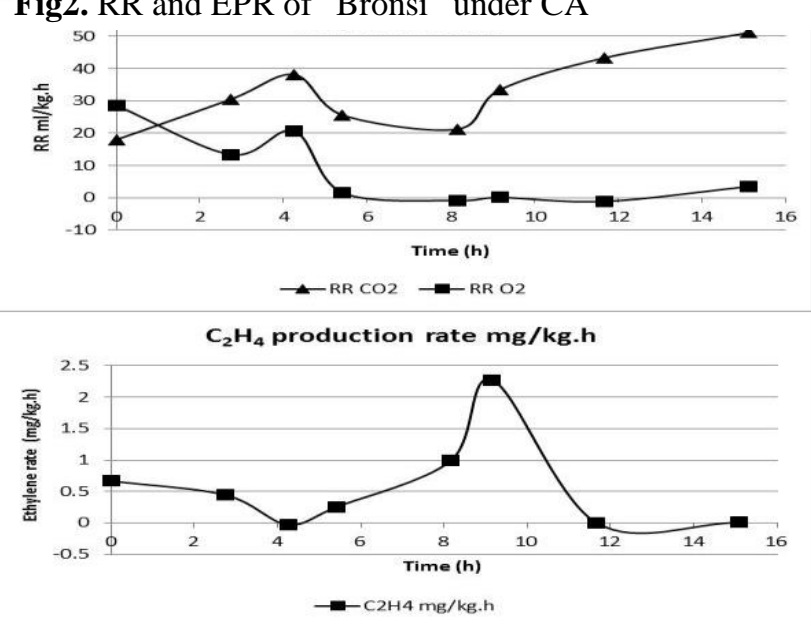

As it can be observed, although accumulated $\mathrm{CO}_{2}$ and depleted $\mathrm{O}_{2}$ followed identified trends, $\mathrm{RR}_{\mathrm{CO} 2}$ and $\mathrm{RR}_{\mathrm{O} 2}$ did not follow so. Rates were quite fluctuating, reaching first peak after 4 hours followed by decline for additional 4 hours. Afterwards, $\mathrm{RR}_{\mathrm{CO} 2}$ continued increasing while $\mathrm{RR}_{\mathrm{O} 2}$ was fairly constant at its minimum values near zero. However, the first $\mathrm{RR}_{\mathrm{CO} 2}$ peak (after 4 hours) was associated with EPR drop, followed by rapid increase until reaching its highest rate at 12 hours, whereupon was again associated with another EPR peak. Contrary, $\mathrm{RR}_{\mathrm{O} 2}$ (upper left) followed a second order polynomial equation with $\mathrm{R}^{2}$ value 0.84 (equation not shown). It is worth mentioning that in a normal respiration process the ratio between $\mathrm{RR}_{\mathrm{CO} 2}$ and $\mathrm{RR}_{\mathrm{O} 2}$ is close to unity. The relation is known as respiration quotient (RQ). In this study however, RQ was away from unity relation, mainly due to fluctuating $\mathrm{RR}_{\mathrm{CO} 2}$. However, as far as we know, RR under controlled atmosphere at high most important activity that occurs during ripening (Kader, 2002). Figure 2 shows accumulated $\mathrm{CO}_{2}$, depleted $\mathrm{O}_{2}, \mathrm{RR}_{\mathrm{CO} 2}$ produced and $\mathrm{RR}_{\mathrm{O} 2}$, as well as accumulated $\mathrm{C}_{2} \mathrm{H}_{4}$ and EPR during the CA treatment for "Bronsi".

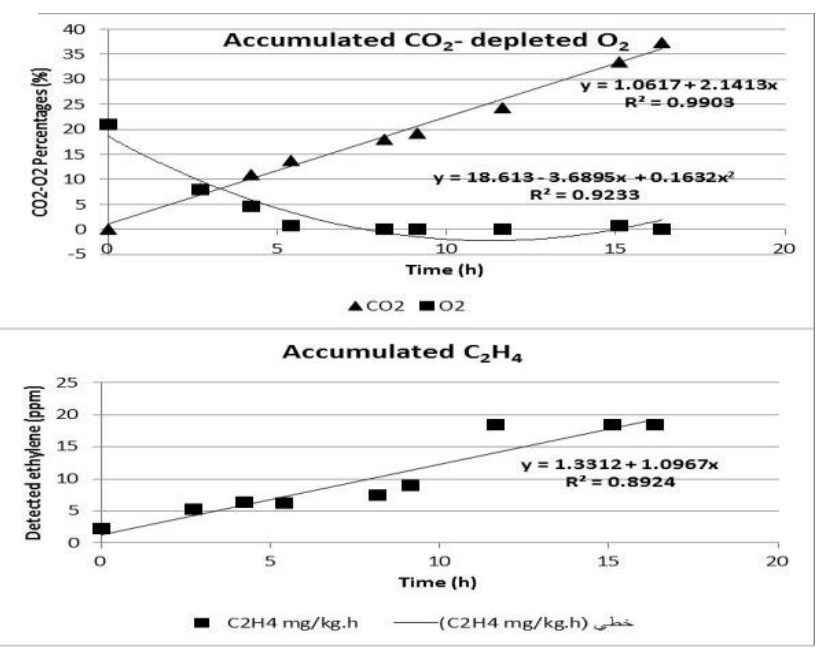

temperature and stressed fruits is rather rare. Nonetheless, RR of dates under controlled atmosphere condition and low temperature had been reported (Fennir et al., 2017). However, those were not under very high $\mathrm{CO}_{2}$ and very low $\mathrm{O}_{2}$. Looking at the graphs, one can notice that first RR peak, first EPR peak and $\mathrm{CO}_{2}$ accumulation as well as $\mathrm{O}_{2}$ depletion trend all occurred at $4.25 \mathrm{~h}$ time. In fact, by all means this not coincidental, we are quite certain that some kind of physiological activity related to ripening took place at this particular time. Most importantly, $\mathrm{O}_{2}$ reaching $4.86 \%$ and after an hour it reached $0.71 \%$. Moreover, another increase in $\mathrm{RR}_{\mathrm{CO} 2}$ started at $8 \mathrm{~h}$ time, this was again associated with increase in EPR, and continued its rise until the second EPR peak which was gain accompanying by $\mathrm{RR}_{\mathrm{CO} 2}$ increase. At this time, high $\mathrm{CO}_{2}$ and $\mathrm{C}_{2} \mathrm{H}_{4}$ concentrations were decidedly believed to play an important role in the ripening process as substantial 


\section{Mohamed Abusaa Fennir and Mohamed Taher Morghem., 2019}

number of fruits changes color and entered Rutab stage. Once again, it is believed that high $\mathrm{CO}_{2}$ concentration in combination with the presence of $\mathrm{C}_{2} \mathrm{H}_{4}$ triggered the ripening process by effecting tannins and reducing astringency in addition to starting the mechanism of converting starch to sugar. However, by about 17 hours of monitoring, high percentage of fruits changed color and became Rutab. Yet, an extra 5 hour time was given to the airtight treatment for assuring the process. Nonetheless, no major changes in air composition were recorded.

Figure 3 shows accumulated $\mathrm{CO}_{2}, \mathrm{O}_{2}, \mathrm{RR}_{\mathrm{CO} 2}$, $\mathrm{RR}_{\mathrm{O} 2}$ and EPR for "Taboni" cultivar. As it can be observed, similar trend in accumulated $\mathrm{CO}_{2}$ and consumed $\mathrm{O}_{2}$ (upper) were recorded, still accumulated $\mathrm{CO}_{2}$ was quite linear whereas depleted
$\mathrm{O}_{2}$ flowed polynomial trend with $\mathrm{R}^{2}=0.98$. Again, accumulated $\mathrm{C}_{2} \mathrm{H}_{4}$ exhibited different trend from "Bronsi", it followed a second order polynomial equation with $\mathrm{R}^{2}=0.97$. Nonetheless, EPR increased almost linearly until reaching its peak at $6.5 \mathrm{mg} . \mathrm{kg}$ ${ }^{1} \cdot \mathrm{h}^{-1}$ after about 20 hours from the start of the CA treatment and followed by sudden drop afterwards.

In RR trends (Figure 3 upper left) $\mathrm{RR}_{\mathrm{CO} 2}$ was quite high while $\mathrm{RR}_{\mathrm{CO} 2}$ was rather low close to zero. Similarities between RR of the two cultivars can be observed, especially in $\mathrm{RR}_{\mathrm{O} 2}$. It is quite evident that $R_{\mathrm{CO} 2}$ was relatively higher than that $\mathrm{RR}_{\mathrm{CO} 2}$, once again leading to observing fluctuating RQ. This may be attributed to biochemical changes that occurred during the ripening process. In this regard, RQ did not give normal trend (close to unity).
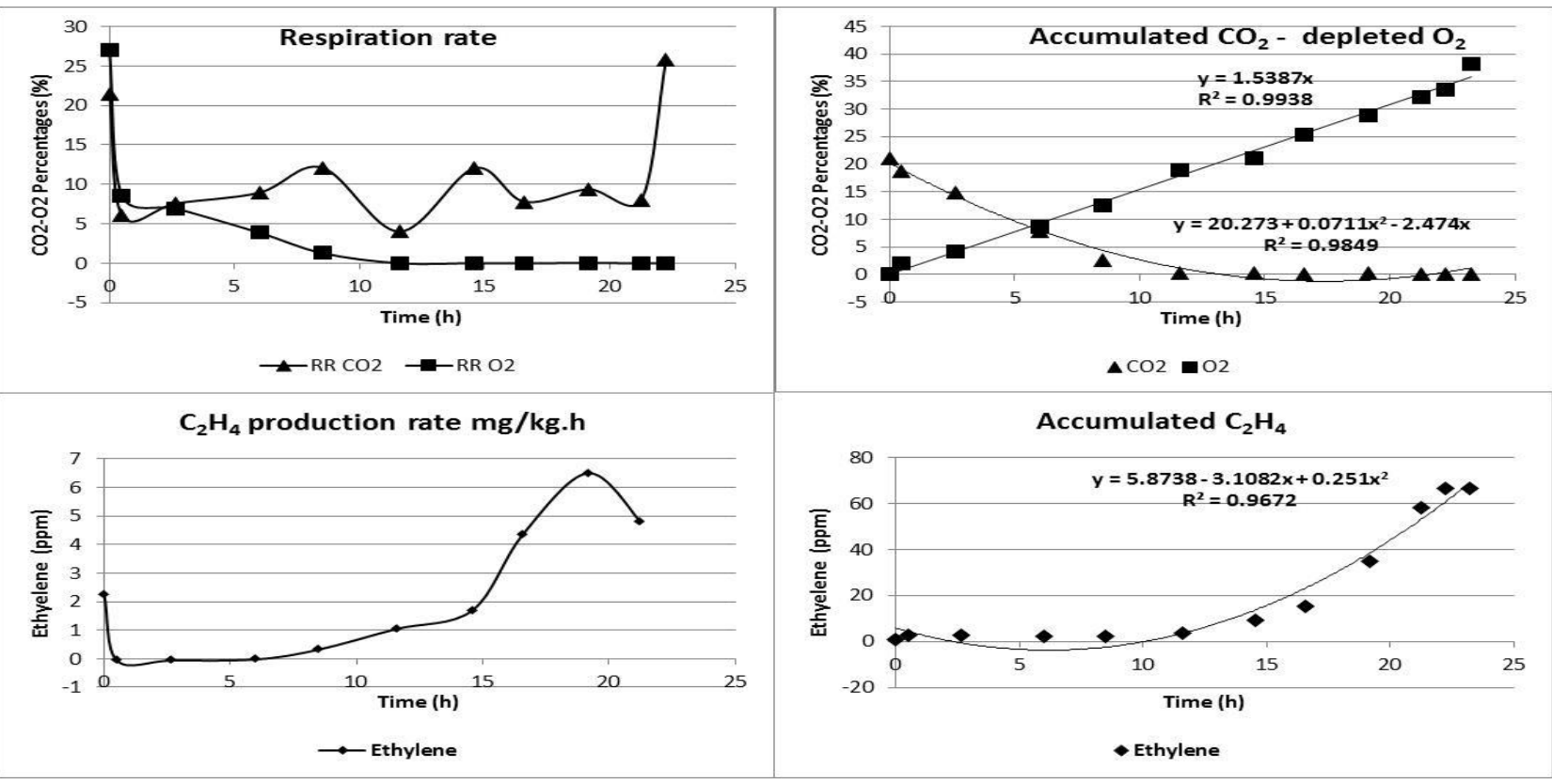

Fig3. RR and EPR for "Taboni" under CA

In general, $\mathrm{RR}_{\mathrm{CO} 2}$ followed normal trend and was in fair agreements with data reported in the literature reported by (Abbas and Ibrahim, 1996), they reported rapid increase in $\mathrm{RR}_{\mathrm{CO} 2}$ for "Hellawi" date cultivar near $63 \mathrm{mg} \cdot \mathrm{kg}^{-1} \cdot \mathrm{h}^{-1}$. However, EPR reported here is also in fairly good agreement with their work. Moreover, they reported EPR of $\left(3.6 \mathrm{mg} \cdot \mathrm{kg}^{-1} \cdot \mathrm{h}^{-1}\right)$ at advanced stage of date fruit development towards ripening. Indeed ethylene plays the decisive role in ripening of all climacteric fruits including dates (Pech et al., 2008). In this regard, it is quite evident that EPR is responsible for initiating the ripening process of the two cultivars. Nonetheless, the ripening process of dates is quite different from other fruits such as tomatoes and banana, yet it is indeed quite complicated at the molecular level (Marondedze et al., 2014) and way beyond this investigation which dealt with the process in relation with controlled atmosphere conditions.

\subsection{Ripening percentages}

As it was mentioned earlier, the ripening process consisted from RA and CA stages. For "Bronsi" the CA stage lasted for 22 hours followed by 23 hours of RA treatment. The first stage led to color change on high percentage of the fruits, while the second stage led to attaining fully ripe fruit color, and enabled completing the spotted fruits and gaining their full ripening color. After 45 hours, it was concluded that the ripening process came to an end. Both ripe and unripe fruits were weighed and percentage was determined at $90.3 \%( \pm 2.52)$. Figure 4 and 5 show color changes from Balah to Rutab for both cultivars. 


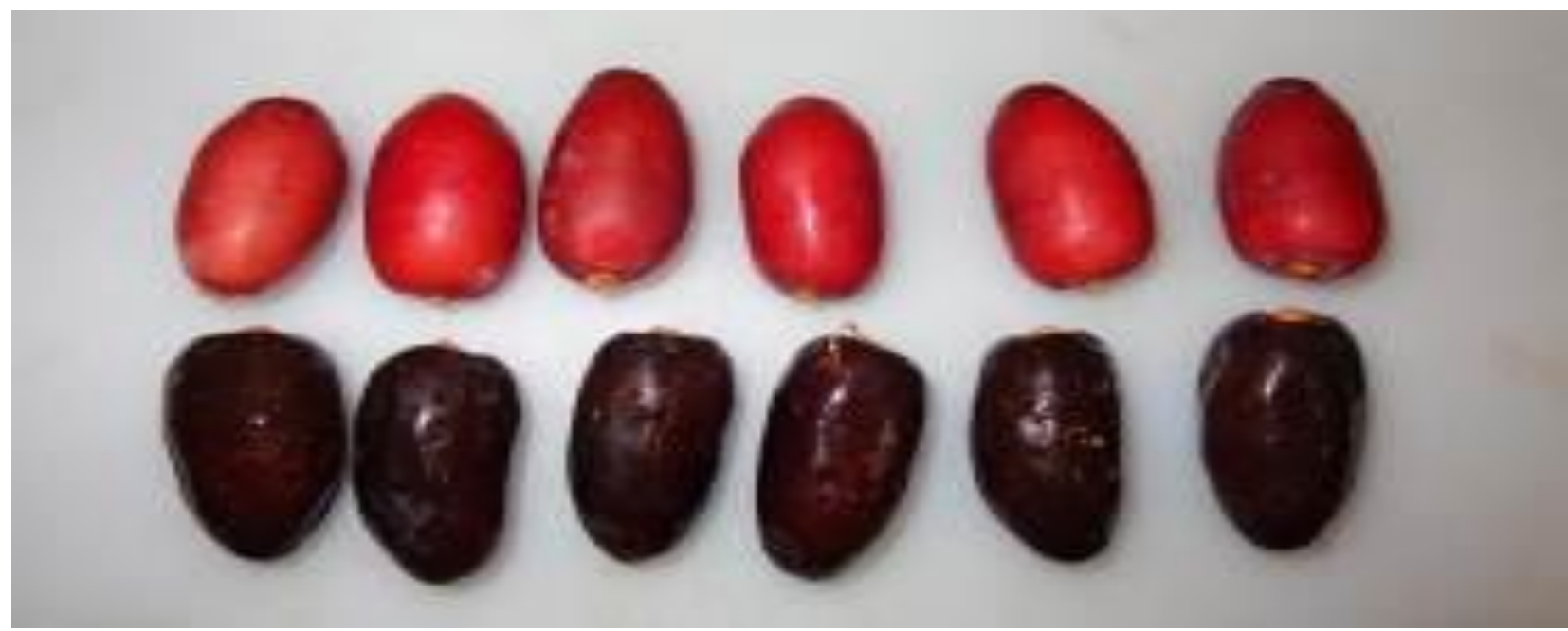

Fig4.Balah and Rutab units for induced ripening of "Bronsi" dates

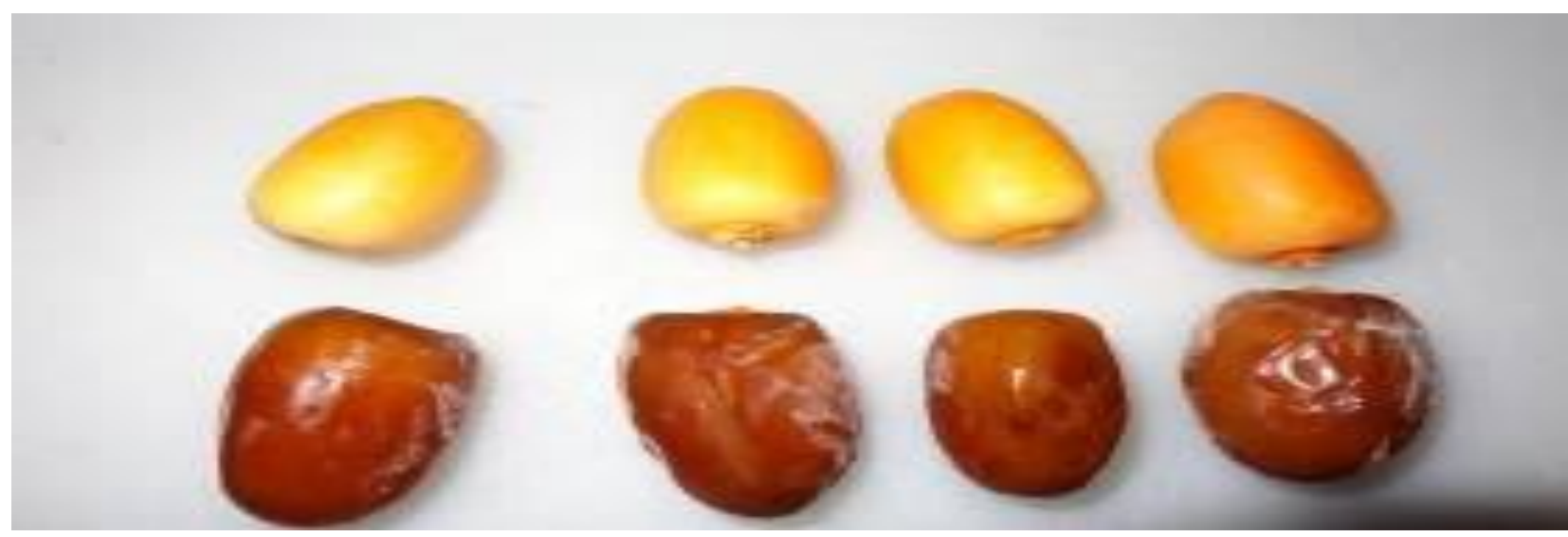

Fig5.Balah and Rutab units for induced ripening of "Taboni" dates

For "Taboni" the CA process lasted for 23 hours and the RA process extended for additional 45 hours, the ripe fruit percentage was $92.33 \%( \pm 3.1)$. It is quite evident that both cultivars responded well to the two stage controlled atmosphere ripening process. Similar treatments were not reported in the literature, with the exception of an old extended report written in 1911 (Freeman, 1911) dealt with the ripening process based on incubation. In the report effect of temperature and relative humidity on ripening of Deglat Noor rates was presented. Nonetheless, the principle of the current study is entirely different, it investigated the effects of temperature, relative humidity in addition to high $\mathrm{CO}_{2}$ and low $\mathrm{O}_{2}$ combined with the effect of $\mathrm{C}_{2} \mathrm{H}_{4}$. Percent-wise, the highest ripening percentage reported in the literature was at $84.65 \%$ for "Shahani" cultivar that was treated with combinations of alcohol, acetic acid and $\mathrm{NaCl}$ (Jahromi, 2015). It is quite evident herein that both cultivars responded will to the treatment applied.

\subsection{Color assessment}

Measured color attributes $\left(\mathrm{L}^{*}, \mathrm{a}^{*}\right.$ and $\left.\mathrm{b}^{*}\right)$ were used in calculating two important color qualities, Hue angle and Chroma. Hue angle was calculated as $\mathrm{Hu}=$ $\tan ^{-1}\left(\mathrm{~b}^{*} / \mathrm{a}^{*}\right)$, while Chroma was calculated as $\mathrm{Cr}=$ $\left(a^{* 2}+b^{* 2}\right)^{1 / 2}$, whereas $L^{*}$ presented the degree of lightness or darkness similar to method applied by (Nunes and Morias, 2002). Nonetheless, Hue is an angle on the color circle $\left(360^{\circ}\right)$. Generally, the circle is divided into four quarters; $0-90^{\circ}$ embodies redpurple Hues, $90-180^{\circ}$ for yellow Hue, $180-270^{\circ}$ for bluish-green, and $270-360^{\circ}$ for blue Hue. Chroma however is the intensity of the Hue itself, while $\mathrm{L}^{*}$ is the color lightness-darkness. Every three particular combinations give specific three dimensional points within Hunter Lab color ball. Figure 6 shows the three color attributes of induced ripening date compared with naturally ripened ones collected from the same tree. Nonetheless, ANOVA analysis showed no significant difference in color attributes between induced and naturally ripened date at $(\mathrm{p}<0.05)$. Also, Hue color attribute of both cultivars fell within the first quarter of color circle that represents redness. Observing color of the two cultivars shown in Figures 4 and 5, "Bronsi" color is quite dark red while "Taboni" is very light, this is clearly shown in Hue angle that shows "Bronsi" in the upper limit of the redness while "Taboni" fell in the lower portion. Same observation can be seen in $\left(\mathrm{L}^{*}\right)$ attribute, 
Mohamed Abusaa Fennir and Mohamed Taher Morghem., 2019

"Taboni" is much lighter than "Bronsi" whereas color than "Taboni". concentration (Chroma) of "Bronsi" is much higher
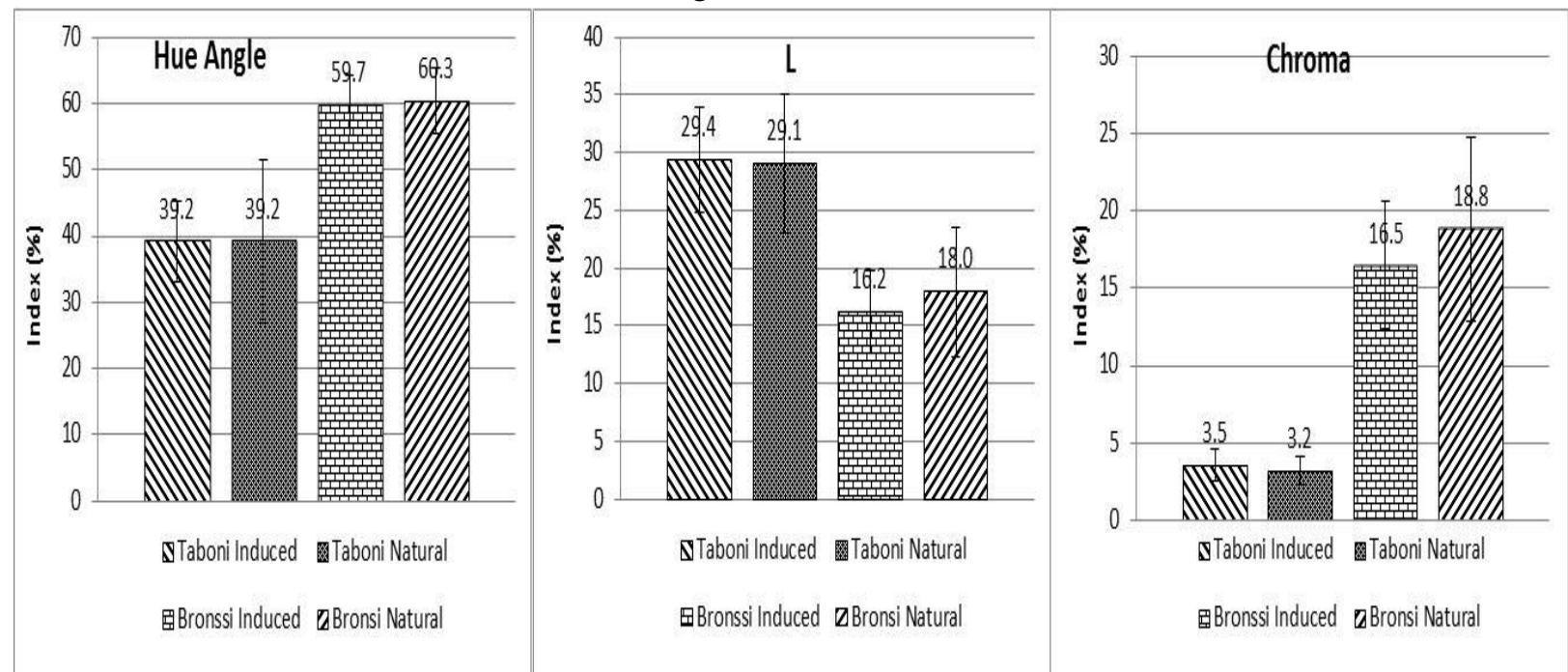

Fig6. Color attributes of induced ripening vs natural ripening of "Bronsi" and "Taboni" dates

\subsection{Sensory analysis}

Quality attributes related to taste were examined by the panel, sweetness, taste and acceptance. Although untrained taste panel was used, results showed no significant difference between induced and natural ripened dates at $(p<0.05)$. Variations among the panel were recorded, that was quite normal mainly because of personal variations. Generally, the induced ripened dates were comparable with naturally ripened dates.

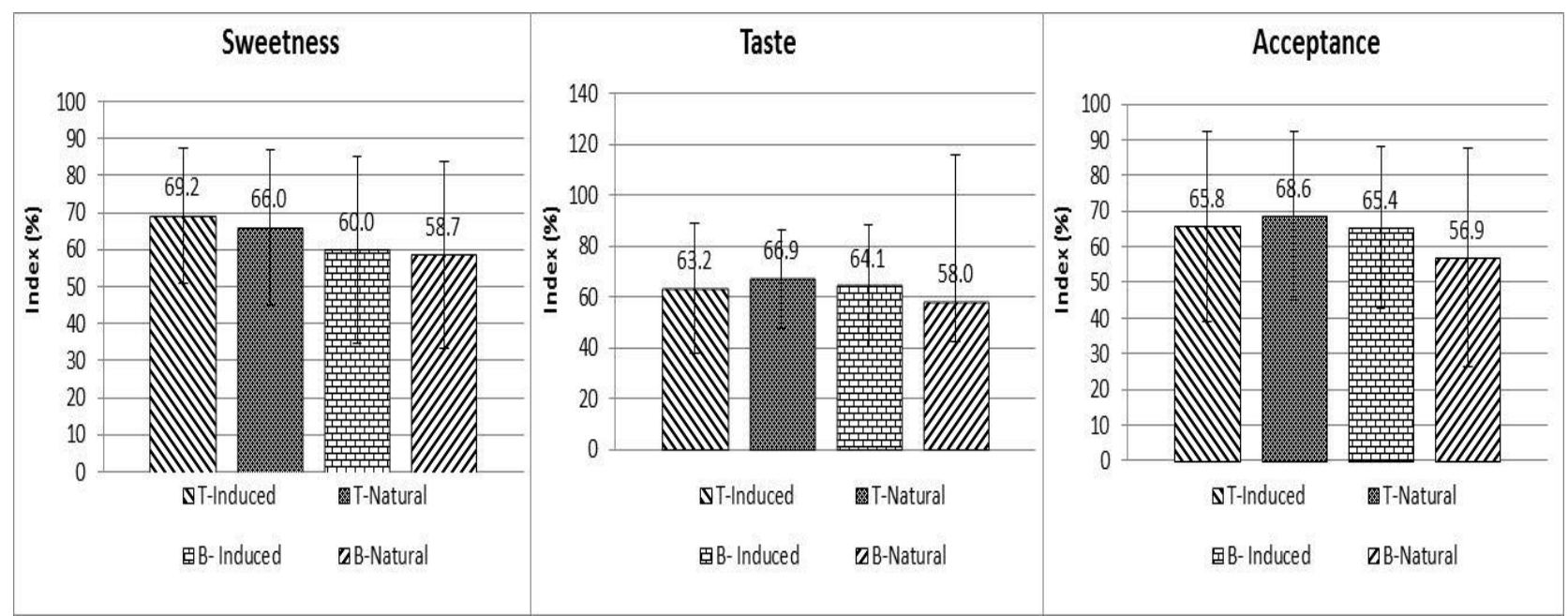

Fig7.Sensory analysis of induced ripened vs naturally ripened dates if the two cultivars (T= "Taboni”, B= "Bronsi")

\section{CONCLUSIONS}

Induced ripening using $\mathrm{CA}$ treatment was investigated using two soft cultivars, "Bronsi" and "Taboni". The ripening process extended for 45 hours and 72 hours for "Bronsi" and "Taboni" cultivars, respectively. It was found that accumulated $\mathrm{CO}_{2}$ and $\mathrm{C}_{2} \mathrm{H}_{4}$, as well as $\mathrm{O}_{2}$ consumed followed linear and second order polynomial relations while RR and EPR did not follow so, instead they showed some associated peaks and those were related to date ripening. Induced ripened dates were not significantly different from naturally ripened dates of the two cultivars in color attributes (L, Chroma and Hue angle), also were not significantly different from naturally ripened dates in sweetness, taste and acceptance. The study demonstrated the potential of using CA treatments for ripening dates and applying the method on other cultivars is highly recommended.

\section{ACKNOWLEDGMENT}

The authors acknowledge the Libyan Authority for Natural Science and Technology for funding the project.

\section{REFERENCES}

Abbas M, Ibrahim MA (1996). The role of ethylene in the regulation of fruit ripening in the Hillawi date palm (Phoenix dactylifera L). J Sci.of Food and Agric. 72:306-308 
Abul-Soad AA (2010). Date Palm in Pakistan, current status and prospective. USAID Firms project. Pp. 86.

Alexander L, Grierson D (2002). Ethylenebiosynthesis and action in tomato: a model for climacteric fruit ripening. Journal of Experimental Botany. 53 ( 377): 2039-2055.

Al-Yahyai R, Manickavasagan A (2012). An Overview of Date Palm Production. In: Dates Production, Processing, Food, and Medicinal Values. Ed. Manickavasagan, A. M. Mohamed Essa E. Sukumar. CRC Press Taylor \& Francis Group. FAO, 2018. FAO statistical data. www.fao.org

Farahnaky A, Askari H, Bakhtiyari M, Majzoobi1 M (2009). Accelerated ripening of kabkab dates using sodium chloride and acetic acid solutions. Iran Agricultural Research, 27 (1). 99-112.

Fennir MA, Morgham MT, Raheel SA (2014). Respiration rates of ten Libyan date cultivars (Phoenix dactylifera) measured at Balah stage. In Proc. 2nd International Conference on Sustainable Environment and Agriculture, San Diego. USA. pp: 31-35.

Fennir MA, Morgham MT, Raheel SA (2017). Response of Libyan Soft Date Cultivars "Hellawi" and "Hurra" at "Balah" Stage to Controlled Atmosphere Conditions. Libyan Journal of Agriculture. (22) (1): 61-73.

Gupta R (2017). Artificial ripening of fruits and effects on health. International Journal of Advanced Technology in Engineering and Science. 5(1): 58-62 Jahromi AA (2015). Field early and even ripening of date palm fruits. Indian Journal of Fundamental and Applied Life Sciences. 5 (2): 68-73

Kader AA (2002). Postharvest biology and technology: An overview. In Postharvest Technology of Horticultural Crops, 3rd ed., Univ. of Calif., Agriculture and Natural Resources, Publication 3311, 2002, pp. 15-20.

Kader AA, Hussein A (2009). Harvesting and postharvest handling of dates. ICARDA, Aleppo, Syria. iv + 15 pp.

Markhand SG, Parveen Z, Abul-Soad AA, Jatoi MA, Saleem SA (2014). Accelerated ripening of var. Aseel dates fruit using sodium chloride and acetic acid solutions. Proceedings of the Fifth International Date Palm Conference: 16-18 March, Abu Dhabi. UAE. pp 363-370.

Marondedze C, Gehring C, Thomas L. (2014). Dynamic changes in the date palm fruit proteome during development and ripening. Horticulture Research. 39:1-15.

McCarthy MA (2012). Date palms in the desert: Reimagining and cooperating with nature in arid Arizona. Arizona Journal of Interdisciplinary Studies. 1: Spring: 39-53.
Mittra S, van Etten V, Franco T (2013). Collecting Weather Data in the Field with High Spatial and Temporal Resolution Using iButtons. Biodiversity International. June Version. 1-30.

Nunes MCN, Morias AMMB (2002). Fruit maturity and temperature influence response of strawberries to controlled atmosphere. J. Amer. Soc. Hort. Sci. 127 (5):836-842.

Oliveira AN, Ramos AM, Minim VRR, Chaves JBP (2011). Sensory stability of whole mango juice: influence of temperature and storage time. Technol.Aliment., Campinas, 32(4): 819-825.

Pech JC, Bouzayen M, Latche A (2008). Climacteric fruit ripening: Ethylene-dependent and independent regulation of ripening pathways in melon fruit.Plant Science.175 (1-2): 114-120.

Racchi ML, Bove A, Turchi A, Bashir G, Battaglia M, Camussi A. (2014). Genetic characterization of Libyan date palm resources by microsatellite markers. 3 Biotech. 4. pp: 21-32.

Rygg GL (1975). Date Development, Handling, and Packing in the United States. Agriculture Handbook No. 482 Agricultural Research Service. United States Department of Agriculture. 55p.

Shamim F, Ali MA, Asghar M, Din A, Babu I, Yasmin Z (2013). Controlled ripening of date palm fruit and impact on quality during postharvest storage. Extensive Journal of Applied Sciences. January 213-1-2: 53-57.

Siddiqui W, Dhua RS (2010). Eating artificially ripened fruits is harmful. Current Science 99 (12):1664-1668 


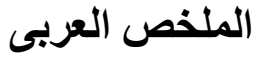 \\ استجابة صنفين من أصناف التمور الليبية الرطبة للانضاج المُحفز تحت ظروف الهواء المعدل \\ محمد أبوصاع فنير' و محمد الطاهر مرغم'

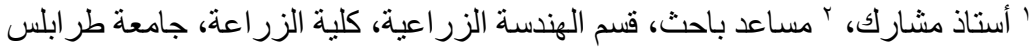

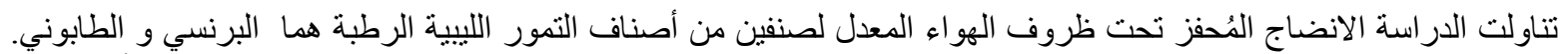

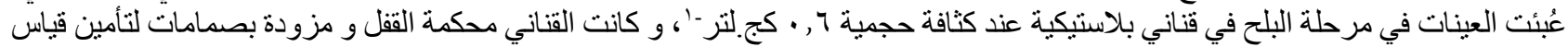

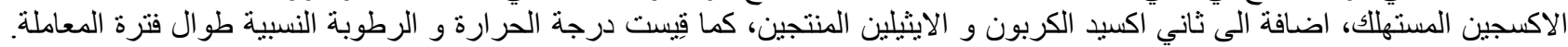

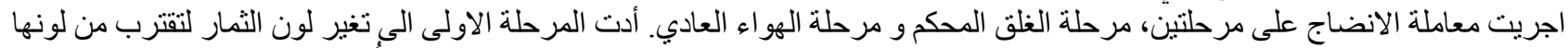

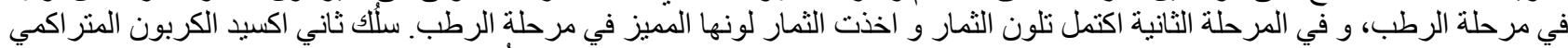

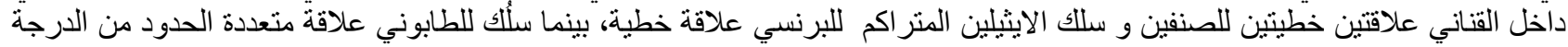



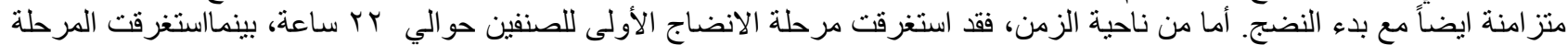

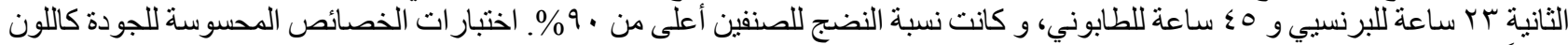

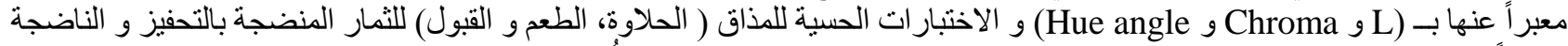

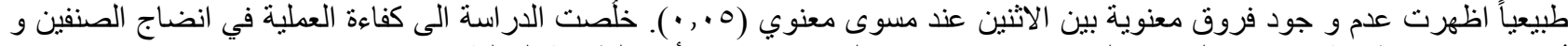
يُوصى باختبار طريقة الانضاج المُحفز على اصناف اخرى من التُن التمور و تحسين أداء الطريقة الحالية. الكلمات الدالة: الانضـاج المحفز، الهو اء المعدل، التمور الرطبة، الايثيلين، ثاني اكسيد الكربون، الاكسجين 